\title{
Is there evidence that competition in healthcare is a good thing? No.
}

We're unhappy with the wording of the original correction that we published for this head to head debate (BMJ 2011;343:d4337, doi:10.1136/bmj.d4337). The following version is more informative:

In his head to head article, Nicholas Mays describes a study by Cooper et al as showing that a one standard deviation increase in the measures of competition was generally associated with only a $0.2-0.3 \%$ greater reduction in acute myocardial infarction death rates than might otherwise have been expected. In fact, Cooper et al's findings imply that a one standard deviation increase in competition led to an absolute reduction of $0.9 \%$ in acute myocardial infarction mortality over three years, from a baseline of $13.8 \%$ in 2006 .

Cite this as: $B M J$ 2011;343:d4494 